\title{
Transport Performance Improvement of a Multiphase Pump for Gas-Liquid Mixture Based on the Orthogonal Test Method
}

\author{
Guangtai Shi, Helin Li, Xiaobing Liu *, Zongku Liu (D) and Binxin Wang
}

Key Laboratory of Fluid and Power Machinery, Ministry of Education, Xihua University, Chengdu 610039, China; shiguangtai_1985@126.com (G.S.); lihelin54@yhwins.com (H.L.); liuzongku@stu.xhu.edu.cn (Z.L.); WangBX077@163.com (B.W.)

* Correspondence: liuxb@mail.xhu.edu.cn

Citation: Shi, G.; Li, H.; Liu, X.; Liu, Z.; Wang, B. Transport Performance Improvement of a Multiphase Pump for Gas-Liquid Mixture Based on the Orthogonal Test Method. Processes 2021, 9, 1402. https://doi.org/ $10.3390 /$ pr9081402

Academic Editor: Krzysztof Rogowski

Received: 18 June 2021

Accepted: 6 August 2021

Published: 13 August 2021

Publisher's Note: MDPI stays neutral with regard to jurisdictional claims in published maps and institutional affiliations.

Copyright: (C) 2021 by the authors. Licensee MDPI, Basel, Switzerland. This article is an open access article distributed under the terms and conditions of the Creative Commons Attribution (CC BY) license (https:// creativecommons.org/licenses/by/ $4.0 /)$

\begin{abstract}
To improve the transport performance of a rotodynamic multiphase pump for a gas-liquid mixture, we took the head and efficiency index at rated flow rate with $15 \%$ inlet gas volume fraction as the indices, and used the orthogonal test design method and CFD technology to optimize. We selected the blade shroud angles at the leading edge and trailing edge, and axial length of the impeller, as well as the inlet incidence angle and blade number of the diffuser, and a total of five factors were used for the orthogonal test. The weight function was used to determine the final trial protocol. The results showed that the blade shroud angle at the trailing edge had the greatest influence on the head and efficiency indices. Under the rated flow rate with a $15 \%$ inlet gas volume fraction, the head and efficiency of the optimized pump were increased by $2.81 \mathrm{~m}$ and $5.6 \%$, respectively, in comparison to the base pump. After the optimization, the partial fast-speed regions at the inlet of the impeller passage and the partial low-pressure regions on the blade suction side of the impeller disappeared, the accumulation of the gas phase on the blade suction side at the impeller outlet was suppressed, and the pumping performance of the impeller using the gas-liquid mixture was improved greatly. This study provides an important theoretical basis for the optimization and design of a multiphase pump.
\end{abstract}

Keywords: multiphase pump; multiphase transport performance; orthogonal test; optimization; weighting function

\section{Introduction}

Energy is closely related to the development of human society. Nowadays, the exploitation and consumption of oil and gas resources is increasing at faster rate. As the onshore oilfields gradually run out of resources, more offshore oilfields are being constructed [1,2]. The crude oil is often mixed with sand, water, and gas when exploited from the abysmal sea. The presence of gas and sand makes the pressurization and transportation of crude oil very difficult. In the process of such pressurization and transportation, the rotodynamic multiphase pump has attractive development prospects, due to its good performance in pumping a high gas volume fraction mixture with particles [3].

Due to the great difference in physical properties between gases and liquids, those two phases separate when pumping a gas-liquid mixture with a rotodynamic multiphase pump. Differing from the liquid phase regarding pressure, the gas phase is likely to accumulate on the impeller hub and blade suction surface [4,5], which reduces the work capacity of the impeller, increases the energy loss, and leads to a rise in pressure, causing the efficiency of the multiphase pump to not meet the requirements of engineering practices [6,7]. In addition, the pressure pulsation in the multiphase pump surges when the gas volume fraction in the pump reaches a certain level, affecting the stable operation of the multiphase pump [8]. Therefore, the design and performance optimization of a rotodynamic multiphase pump is always an important area for research. Combining CFD direct analysis and reverse design method, Cao [9] used a specified velocity moment distribution to design the impeller of a multiphase pump, with experimental results verifying a wide range of 
high efficiencies of the impeller. Li [10] considered the compressibility of the gas phase and designed the pressurization units of a multiphase pump by resizing the hub diameters and blade angles stage by stage, with numerical results proving a significant increase in the efficiency of the improved pump when IGVF $=50 \%$ (IGVF: inlet gas volume fraction), accompanied by a reduced hydraulic loss at the inlet of the impellers. Shi [11] used a split in the middle of the impeller blades and found that the gas phase accumulated on the blade suction side in the impeller and entered into the adjacent flow channel through the split, which improved the uniformity of the gas and liquid phases in the impeller passage, thus improving the transport performance for a gas-liquid mixture in the multiphase pump. $\mathrm{Xu}$ [12] conducted tests on impellers with and without splitter blades, and found that the impeller with splitter blades had a higher head under pure water conditions and a wider range of high efficiency under gas-liquid two-phase conditions.

Apart from the design and modification, a test design analysis method, approximate mathematical model, and intelligent optimization algorithm have been used by scholars to optimize the pump. The commonly used test design methods include the orthogonal test design method, optimal Latin superposition method, and central group method. All of these test design methods can be applied to train an approximate mathematical model. An intelligent optimization algorithm generally is combined with an approximate mathematical model to optimize the geometric parameters of a pump. Frequently used intelligent optimization algorithms include the genetic algorithm and particle swarm optimization. Liu [13] applied the fourth-order function to calculate the blade angle of the impeller and the first-order function to calculate the blade angle of the diffuser, then combined with the orthogonal test method to search the optimal coefficients of the functions. Results showed that a pressure rise of $12.8 \mathrm{kPa}$ at the rated flow rate with IGVF $=10 \%$ occurred in the optimized pump. Kim [14,15] and Suh [16] employed the response surface method as an approximate mathematical model to optimize a multiphase pump. Although there may be cases of inaccurate optimization of geometric parameters with the test design method and approximate mathematical model, the combination of an intelligent optimization algorithm and approximate mathematical model can optimize the pump more comprehensively and accurately. Zhang [17] and Hu [18] used artificial neural networks as an approximate mathematical model and optimized the multiphase pump with a genetic algorithm. Junwon [19] employed the response surface method as an approximate mathematical model and optimized a multiphase pump with an evolutionary algorithm.

Though the optimization for geometric parameters may be more comprehensive and accurate when an intelligent optimization algorithm conducts optimization for geometric parameters with an approximate mathematical model, it also needs plenty of time and test cases. The orthogonal test design method is a fast and efficient test design method suitable for multiple factors that selects part of the most representative samples from all possible samples according to the idea of equilibrium distribution. It can estimate the influence law among various parameters of the model based on range analysis, and therefore greatly reduce the number of test samples. Many scholars have successfully improved the performance of the pump using the orthogonal test design method [20-22].

Although scholars have optimized the impeller of a rotodynamic multiphase pump with the orthogonal test design method, no study has optimized the impeller and diffuser or taken the head and efficiency as the optimized indices simultaneously. In this study, a pressurization unit of the self-developed rotodynamic multiphase pump was taken as the optimized object. The blade shroud angles at the leading and trailing edge of the impeller, as well as the axial length of the impeller, were chosen as the test factors. Combined with the theory of binary flow, diffusers matched with the impellers were designed, and the number of blades and inlet incidence angle of the diffuser were selected as the test factors. According to the principle of orthogonal tests, an orthogonal test scheme using five factors and four levels was designed. Under the rated flow rate $\left(Q=100 \mathrm{~m}^{3} / \mathrm{h}\right)$ with IGFV $=15 \%$, the head and efficiency were taken as the optimized indices, and the weight function was 
combined to accomplish the optimization of the multiphase transport performance of the multiphase pump.

\section{Optimized Object}

A rotodynamic multiphase pump mainly consists of a suction chamber, multiple pressurization unit, and a volute, of which the pressurization unit is the core pressurization component of the pump and has the greatest influence on the pump's performance. Therefore, we selected the pressurization unit of the rotodynamic multiphase pump as the optimization object, including the impeller and diffuser. Its entity structure is shown in Figure 1, and the main designed parameters were as follows: rated flow rate $\mathrm{Q}_{\mathrm{d}}=100 \mathrm{~m}^{3} / \mathrm{h}$; designed head $\mathrm{H}=16.5 \mathrm{~m}(\mathrm{IGVF}=0)$; efficiency $\eta=67.7 \%(\mathrm{IGVF}=0)$; rated speed $n=3000 \mathrm{r} / \mathrm{min}$. The major geometric parameters are shown in Table 1 .

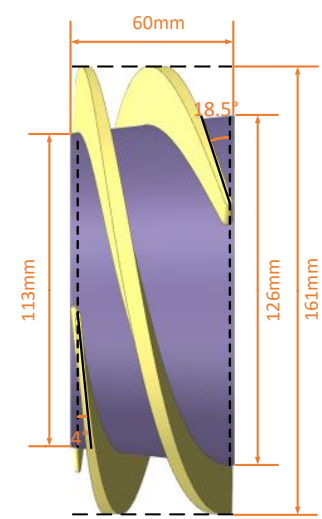

Impeller

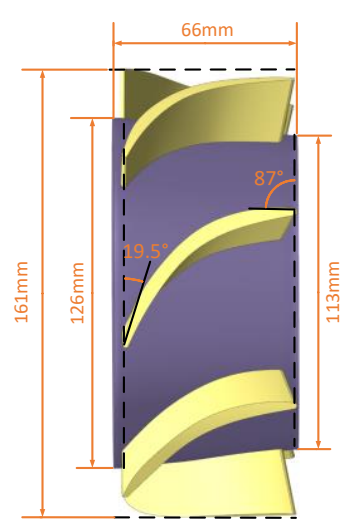

Diffuser

Figure 1. Entity models of the impeller and diffuser.

Table 1. Major geometric parameters of the impeller and diffuser.

\begin{tabular}{ccc}
\hline Parameter & Impeller & Diffuser \\
\hline Number of blades, $\mathrm{Z}$ & 3 & 7 \\
Blade shroud angle at the leading edge, $\beta_{\mathrm{I}, \mathrm{s} 1}\left(^{\circ}\right)$ & 4 & 19.5 \\
Blade shroud angle at the trailing edge, $\beta_{\mathrm{I}, \mathrm{s} 2}\left(^{\circ}\right)$ & 18.5 & 87 \\
Shroud diameter at the inlet $(\mathrm{mm})$ & 161 & 161 \\
Inlet hub ratio & 0.7 & 0.78 \\
Axial length, $\mathrm{L}(\mathrm{mm})$ & 60 & 66 \\
\hline
\end{tabular}

\section{Numerical Method}

\subsection{Numerical Simulation Model and Mesh Generation}

With the rapid development of computers, CFD simulation can accurately describe the flow of fluid in a pump [23]. In the current study, a certain length of pipe section was added in front of the impeller and behind the diffuser, which ensured the stability of the flow in the impeller and diffuser. Therefore, the numerical simulation model consisted of four parts: the inlet pipe, water domain of the impeller, water domain of the diffuser, and outlet pipe. The model's structure is shown in Figure 2.

In this numerical simulation model, considering the simple structure of the inlet and outlet pipes, an ANSYS mesh was employed to generate the hexahedron mesh for them. The models of the impeller and diffuser were generated by ANSYS BladeGen and then imported into ANSYS TurboGrid to generate the structural mesh. In order to accurately capture the flow in the near-wall surfaces, boundary layers were added in the near-wall surfaces of the impeller and diffuser. 


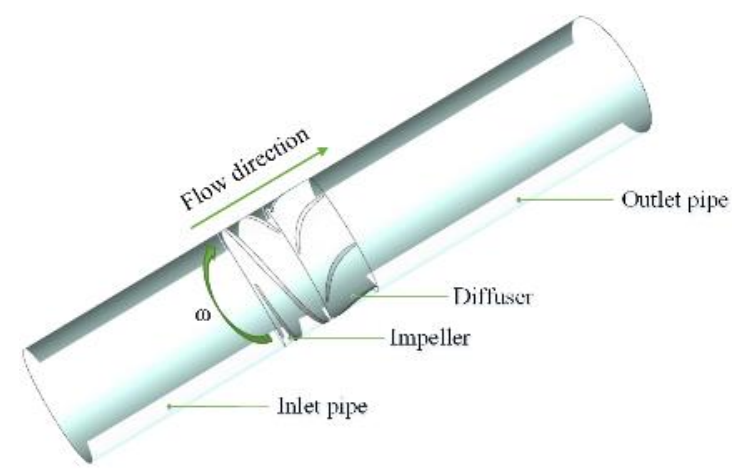

Figure 2. Numerical model.

The larger the number of the grid, the more accurate the numerical simulation it can realize, but a longer simulation time will be required. Considering the use of computing resources, the independence test of the mesh number was conducted with the base pump under the rated flow rate and a pure water condition (IGVF $=0)$. As shown in Table 2, the mesh number of the inlet and the outlet pipes was set at 999,372, and the mesh numbers of the impeller and diffuser were increased to 890,604 and 1,067,976, respectively. The variation range of the head and efficiency of the multiphase pump was less than $0.5 \%$, and the mesh number of the entire computational domain was finally set at 2.96 million. Figure 3 shows the mesh distribution of the impeller and diffuser passages. The parameters set for the mesh generation remained constant when ANSYS TurboGrid was used to generate the mesh of different models, which ensured the accuracy of the mesh of the different models.

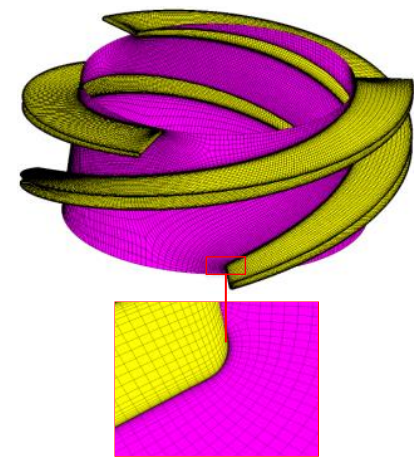

(a)

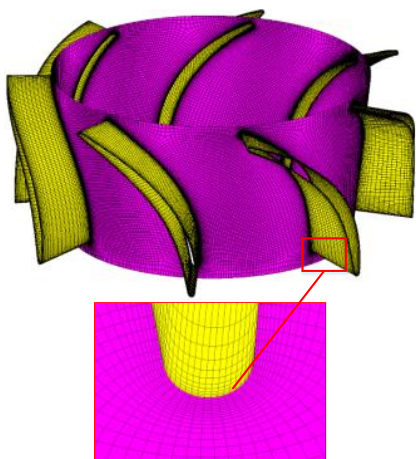

(b)

Figure 3. Mesh distribution of the impeller and diffuser passages. (a) Impeller; (b) diffuser.

Table 2. Distribution of the grid numbers.

\begin{tabular}{ccccc}
\hline & Grid 1 & Grid 2 & Grid 3 & Grid 4 \\
\hline Inlet pipe & 147,975 & 233,662 & 376,629 & 627,748 \\
Impeller & 286,704 & 577,164 & 890,604 & $1,163,670$ \\
Diffuser & 373,912 & 611,856 & $1,067,976$ & $1,131,264$ \\
Outlet pipe & 247,000 & 391,248 & 622,743 & $1,042,788$ \\
Total number & $1,055,591$ & $1,813,930$ & $2,957,952$ & $3,965,470$ \\
$H_{\mathrm{n}} / H_{1}$ & 1 & 1.0090 & 1.0025 & 0.9988 \\
$\eta_{\mathrm{n}} / \eta_{1}$ & 1 & 0.9901 & 0.9905 & 0.9886 \\
\hline
\end{tabular}

The $\mathrm{y}^{+}$of the impeller and diffuser blades is displayed in Figure 4. As shown in Figure 4, the $\mathrm{y}^{+}$of the impeller and diffuser blade surface was 0-60 and 0-100, respectively. which met the requirements of the turbulence model and scalable wall function. The basic idea behind the scalable wall function approach is to limit the $\mathrm{y}^{+}$value used in the 
logarithmic formulation to a lower value. It can avoid the deterioration of the calculation results when $\mathrm{y}^{+}<15$, and can obtain a consistent solution for an arbitrarily refined grid.

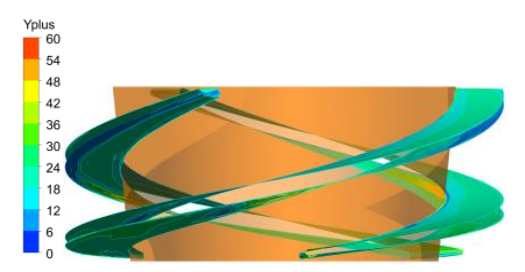

(a)
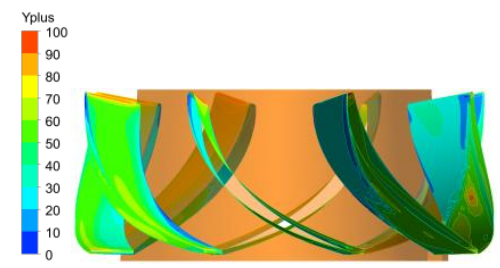

(b)

Figure 4. The $\mathrm{y}^{+}$distribution of the blade surfaces. (a) Impeller; (b) diffuser.

\subsection{Numerical Methods and Boundary Conditions}

ANSYS CFX software was used to solve the Reynolds time-averaged N-S equation of fixed length. Under the gas-liquid two-phase conditions, the liquid and gas phases were selected as water and air at $25^{\circ} \mathrm{C}$, respectively; water was set as the continuous phase, while air at $25^{\circ} \mathrm{C}$ was the regarded as dispersed phase, and existed in the form of bubbles with the same diameter. The Eulerian-Eulerian model served as the gas-liquid two-phase simulation model, the $k-\omega$ (SST) model was applied for the liquid phase, and the dispersed-phase zero equation model was applied for the gas phase and the drag force between the gas phase and liquid phase due to the relative slip between the two phases. The grace model was selected as the drag force model [24], and the $k-\omega$ (SST) turbulence model also was used to simulate pure water conditions.

The RANS equations given as Equations (1) and (2):

$$
\begin{gathered}
\frac{\partial \overline{u_{i}}}{\partial x_{i}}=0 \\
\overline{u_{j}} \frac{\partial \overline{u_{i}}}{\partial x_{j}}=-\frac{1}{\rho} \frac{\partial p}{\partial x_{i}}\left(v \frac{\partial \overline{u_{i}}}{\partial x_{j}}-\overline{u_{i}^{\prime} u_{j}^{\prime}}\right)
\end{gathered}
$$

where $i, j=1,2,3 ; u_{i}$ is the averaged component of velocity; $p$ denotes the pressure; $\rho$ is the density of fluid; $v$ is the kinematic viscosity; and $u_{i}^{\prime}$ and $\overline{u_{i}^{\prime} u_{j}^{\prime}}$ denote the fluctuating component of flow velocity and Reynolds stress tensor, respectively.

The $k$ - $\omega$ SST turbulence model is a two-equation model, including turbulent kinetic energy Equation (3) and turbulent frequency Equation (4):

$$
\begin{aligned}
& \rho \frac{\partial k}{\partial t}+\rho v_{j} \frac{\partial k}{\partial x_{j}}=\frac{\partial}{\partial x_{j}}\left[\left(u+\frac{u_{t}}{\sigma_{k}}\right) \frac{\partial k}{\partial x_{j}}\right]+u_{t} \frac{\partial v_{j}}{\partial x_{i}}\left(\frac{\partial v_{j}}{\partial x_{i}}+\frac{\partial v_{i}}{\partial x_{j}}\right)-\beta^{*} \rho k w \\
& \rho \frac{\partial w}{\partial t}+\rho v_{j} \frac{\partial w}{\partial x_{j}}=\frac{\partial}{\partial x_{j}}\left[\left(u+\frac{u_{t}}{\sigma_{w}}\right) \frac{\partial w}{\partial x_{j}}\right]+\frac{\alpha w}{k} u_{t} \frac{\partial v_{j}}{\partial x_{i}}\left(\frac{\partial v_{j}}{\partial x_{i}}+\frac{\partial v_{i}}{\partial x_{j}}\right)-\beta \rho k w^{2} \\
& +2\left(1-F_{1}\right) \rho \frac{1}{w \sigma_{w}} \frac{\partial k}{\partial x_{j}} \frac{\partial w}{\partial x_{j}}
\end{aligned}
$$

where $w$ is the turbulent kinetic energy dissipation ratio; $\rho$ is the medium density; $\mu$ is the viscosity; and the blending function $F_{1}$ is defined by:

$$
F_{1}=\tanh \left\{\min \left\{\max \left[\left(\frac{\sqrt{k}}{\beta^{*} \rho}, \frac{500 v}{y^{2} \omega}\right), \frac{4 \rho \sigma_{\omega 2} k}{C D_{k w} y^{2}}\right]\right\}^{4}\right\}
$$

where $y$ is the distance to the nearest wall, and the turbulent eddy viscosity is defined as follows:

$$
v_{t}=\frac{a_{1} k}{\max \left(a_{1} \omega, S F_{2}\right)}
$$


The constants for this model were: $\beta^{*}=0.09 ; a_{1}=5 / 9 ; \sigma_{\omega 2}=0.856$.

Boundary conditions and solver control settings: the static pressure was specified at the inlet boundary; the dispersed gas phase at the inlet of the model uniformly mixed with the continuous liquid phase; and the volume fractions of the liquid phase and gas phase were set. The grace model was used to calculate the drag force of the gas phase; the bulk mass flow rate, which is the total mass of the gas phase and liquid phase, was taken as the outlet boundary. No-slip wall conditions were utilized for all the wall surfaces. A frozen rotor was employed to connected the interface of the rotating domain (impeller) and adjacent stationary domain (inlet pipe, diffuser), and the connection between the stationary domains (diffuser, outlet pipe) was set as the general connection. The advection scheme and turbulence numerics were selected with high resolution, which made the solution more accurate. The root mean square (RMS) was selected as the convergence scheme, and the convergence accuracy was set at $10^{-5}$.

\section{Design of the Orthogonal Test}

(1) Definition of the test purpose and optimized index: the purpose of this study was to improve the gas-liquid transport performance of a rotodynamic multiphase pump. Under the designed flow rate $\left(\mathrm{Q}=100 \mathrm{~m}^{3} / \mathrm{h}\right)$ with $15 \%$ inlet gas volume fraction, the head and efficiency of the multiphase pump were taken as the optimized indices.

(2) Selection of the test factors: domestic research of rotodynamic multiphase pumps is relatively recent, so there is a lack of sufficient theoretical basis and design experience. According to references $[15-17,25,26]$ and others, for the impeller of a rotodynamic multiphase pump, the blade angles at the leading and trailing edges, inlet hub ratio, half cone angle, and axial length all have a great influence on the transport performance of a multiphase pump impeller for a gas-liquid mixture. Changes in the inlet hub ratio and half cone angle will change the flow angles at the inlet and outlet of the impeller. Therefore, when the inlet hub ratio, half cone angle, and blade angle are selected as the test factors simultaneously, the accuracy of the orthogonal test analysis will be affected. Therefore, the three parameters of the impeller, blade shroud angles at the leading and trailing edges, and axial length were selected as the test factors.

The matching of the impeller and diffuser is very important for the pump [27]. For the diffuser of a rotodynamic multiphase pump, the blade angles at the leading and trailing edges and the number of blades have a great influence on the performance of the diffuser. A rotodynamic multiphase pump needs multiple pressurization units in series to pump fluid, so the blade angle at the trailing edge of the diffuser remains unchanged, fixed at $87^{\circ}$. The flow angle at the diffuser inlet varies with the change of the blade angle at the trailing edge of the impeller, so the diffuser of the base pump no longer matches with the designed impellers in the orthogonal test. Based on the assumption of infinite blade numbers, the flow angle at the impeller outlet is equal to the blade angle. Combining the assumption that the velocity moment at the outlet of the impeller is equal to the velocity moment at the inlet of the diffuser with the correlation of the velocity triangle between the impeller outlet and the diffuser inlet, the flow angles at the inlet of the diffuser are calculated as $\beta_{\mathrm{D}, 1}^{\prime}$. The blade angle at the leading edge of the diffuser is $\beta_{\mathrm{D}, 1}=\beta_{\mathrm{D}, 1}^{\prime}+\Delta \beta_{\mathrm{D}}$, where $\Delta \beta_{\mathrm{D}}$ is the inlet incidence angle of the diffuser.

$$
\begin{gathered}
\left(u_{\mathrm{I}, 2}-\frac{c_{m \mathrm{I}, 2}}{\tan \beta_{\mathrm{I}, 2}}\right) d_{\mathrm{I}, 2}=\left(\frac{c_{m \mathrm{D}, 1}}{\tan \beta_{\mathrm{D}, 1}}\right) d_{\mathrm{D}, 1} \\
C_{m}=\frac{Q}{\frac{\pi\left(d_{s}^{2}-d_{h}^{2}\right)}{4}} \\
u=\frac{\pi d n}{60}
\end{gathered}
$$


where $u$ is the circumferential velocity; $c_{m}$ is the axial component of the absolute velocity; $\beta$ is the blade angle; $d$ is the impeller diameter; $Q$ is the volume flow rate; and $n$ is the rotation speed. The subscript " ${ }_{\mathrm{I}, 2}$ " denotes the trailing edge of the impeller blade; the subscript "D,1" denotes the leading edge of the diffuser blade; and the subscripts " $h$ " and " $s$ " denote the hub and shroud, respectively.

Five test factors were selected for the multiphase pump in the orthogonal test: the blade shroud angle at the leading edge $\left(\beta_{\mathrm{I}, \mathrm{s} 1}\right)$, blade shroud angle at the trailing edge $\left(\beta_{\mathrm{I}, \mathrm{s} 2}\right)$, axial length $(\mathrm{L})$ selected for the impeller, inlet incidence angle $\left(\Delta \beta_{\mathrm{D}}\right)$, and number of blades $\left(Z_{D}\right)$ were selected for the diffuser. Four levels were selected for each factor, as shown in Table 3. The impeller blade number was 3. To avoid the resonance between the impeller and diffuser, the case of 9 diffuser blades was excluded from the scheme of this optimization.

Table 3. Levels of factors.

\begin{tabular}{cccccc}
\hline \multirow{2}{*}{ Level } & \multicolumn{5}{c}{ Factor } \\
\cline { 2 - 6 } & $\begin{array}{c}\boldsymbol{\beta}_{\mathbf{I}, \mathbf{s 1}} \\
\left({ }^{\circ}\right)\end{array}$ & $\begin{array}{c}\boldsymbol{\beta}_{\mathbf{I}, \mathbf{s} 2} \\
\left({ }^{\circ}\right)\end{array}$ & $\begin{array}{c}\mathbf{L} \\
(\mathbf{m m})\end{array}$ & $\begin{array}{c}\Delta \boldsymbol{\beta}_{\mathbf{D}} \\
\left({ }^{\circ}\right)\end{array}$ & $\begin{array}{c}\mathbf{Z}_{\mathbf{D}} \\
-\end{array}$ \\
\hline 1 & 3 & 17 & 58 & 0 & 7 \\
2 & 4 & 18.5 & 60 & 2 & 8 \\
3 & 5 & 20 & 62 & 4 & 10 \\
4 & 6 & 21.5 & 64 & 6 & 11 \\
\hline
\end{tabular}

(3) Relevant calculation of the blade angle and flow angle: after the level of the blade shroud angles at the leading and trailing edges of the impeller was determined, in order for the fluid in different blade heights of the impeller to obtain a similar head, according to the principle of radial lead equality (Equation (4)), we calculated the blade hub angles at the leading and trailing edges of the impeller. The calculated data is shown in Tables 4 and 5. According to Equations (7)-(9), we calculated the inlet flow angles at the shroud and hub of the diffuser corresponding to the blade angles at the outlet of the different impellers. The calculation data is shown in Table 6.

$$
d_{s} \tan \beta_{s}=d_{h} \tan \beta_{h}
$$

where $\beta$ is the blade angle and $d$ is the impeller diameter. The subscripts " $h$ " and "s" denote the hub and shroud, respectively.

Table 4. The impeller's leading-edge blade shroud angles and the corresponding blade hub angles.

\begin{tabular}{ccccc}
\hline Blade angle shroud $\left(^{\circ}\right)$ & 3 & 4 & 5 & 6 \\
\hline Blade angle hub $\left(^{\circ}\right)$ & 4.27 & 5.69 & 7.11 & 8.52 \\
\hline
\end{tabular}

Table 5. The impeller's trailing-edge blade shroud angles and the corresponding blade hub angles.

\begin{tabular}{ccccc}
\hline Blade angle shroud $\left({ }^{\circ}\right)$ & 17 & 18.5 & 20 & 21.5 \\
Blade angle hub $\left(^{\circ}\right)$ & 21.34 & 23.15 & 24.94 & 26.72 \\
\hline
\end{tabular}

Table 6. The calculated corresponding flow angles at the diffuser inlet.

\begin{tabular}{cccccccccc}
\hline & \multicolumn{1}{c}{ Location } \\
\hline Angle & \multicolumn{3}{c}{ Shroud } & \multicolumn{5}{c}{ Hub } \\
\hline Blade angle at the outlet $\left(^{\circ}\right)$ & 17 & 18.5 & 20 & 21.5 & 21.34 & 23.15 & 24.94 & 26.72 \\
Flow angle at the inlet $\left(^{\circ}\right)$ & 14.37 & 13.43 & 12.73 & 12.17 & 17.19 & 16.14 & 15.35 & 14.73 \\
\hline
\end{tabular}


(4) Development of the orthogonal test table: based on the orthogonal test principle, the orthogonal test scheme using a five-factor and four-level $\mathrm{L}_{16}\left(4^{5}\right)$ was designed, as shown in Table 7. This was used to assess the influence law of five test factors on the head and efficiency indices of the multiphase pump. A, B, C, D, and E are the values of the level corresponding to $\beta_{\mathrm{I}, \mathrm{s} 1}, \beta_{\mathrm{I}, \mathrm{s} 2}, \mathrm{~L}, \Delta \beta_{\mathrm{D}}$, and $\mathrm{Z}_{\mathrm{D}}$, respectively.

Table 7. The orthogonal test scheme.

\begin{tabular}{|c|c|c|c|c|c|c|c|c|c|c|}
\hline Trial No. & $\mathbf{A}$ & B & C & D & E & $\begin{array}{c}\beta_{\mathrm{S}, \mathrm{I} 1} \\
\left.{ }^{\circ}\right)\end{array}$ & $\begin{array}{c}\beta_{\mathrm{S}, \mathrm{I} 2} \\
\left({ }^{\circ}\right)\end{array}$ & $\underset{(\mathrm{mm})}{\mathrm{L}}$ & $\begin{array}{c}\Delta \beta_{\mathrm{D}} \\
\left(^{\circ}\right)\end{array}$ & $\begin{array}{r}Z_{D} \\
(-)\end{array}$ \\
\hline 1 & $\mathrm{~A}_{1}$ & $\mathrm{~B}_{1}$ & $\mathrm{C}_{1}$ & $D_{1}$ & $E_{1}$ & 3 & 17 & 58 & 0 & 7 \\
\hline 2 & $\mathrm{~A}_{1}$ & $\mathrm{~B}_{2}$ & $\mathrm{C}_{2}$ & $D_{2}$ & $E_{2}$ & 3 & 18.5 & 60 & 2 & 8 \\
\hline 3 & $\mathrm{~A}_{1}$ & $\mathrm{~B}_{3}$ & $\mathrm{C}_{3}$ & $\mathrm{D}_{3}$ & $E_{3}$ & 3 & 20 & 62 & 4 & 10 \\
\hline 4 & $\mathrm{~A}_{1}$ & $\mathrm{~B}_{4}$ & $\mathrm{C}_{4}$ & $\mathrm{D}_{4}$ & $E_{4}$ & 3 & 21.5 & 64 & 6 & 11 \\
\hline 5 & $\mathrm{~A}_{2}$ & $\mathrm{~B}_{1}$ & $\mathrm{C}_{2}$ & $D_{3}$ & $E_{4}$ & 4 & 17 & 60 & 4 & 11 \\
\hline 6 & $\mathrm{~A}_{2}$ & $\mathrm{~B}_{2}$ & $\mathrm{C}_{1}$ & $\mathrm{D}_{4}$ & $E_{3}$ & 4 & 18.5 & 58 & 6 & 10 \\
\hline 7 & $\mathrm{~A}_{2}$ & $\mathrm{~B}_{3}$ & $\mathrm{C}_{4}$ & $D_{1}$ & $E_{2}$ & 4 & 20 & 64 & 0 & 8 \\
\hline 8 & $\mathrm{~A}_{2}$ & $\mathrm{~B}_{4}$ & $\mathrm{C}_{3}$ & $D_{2}$ & $E_{1}$ & 4 & 21.5 & 62 & 2 & 7 \\
\hline 9 & $\mathrm{~A}_{3}$ & $B_{1}$ & $\mathrm{C}_{3}$ & $D_{4}$ & $E_{2}$ & 5 & 17 & 62 & 6 & 8 \\
\hline 10 & $\mathrm{~A}_{3}$ & $\mathrm{~B}_{2}$ & $\mathrm{C}_{4}$ & $D_{3}$ & $\mathrm{E}_{1}$ & 5 & 18.5 & 64 & 4 & 7 \\
\hline 11 & $\mathrm{~A}_{3}$ & $\mathrm{~B}_{3}$ & $\mathrm{C}_{1}$ & $D_{2}$ & $E_{4}$ & 5 & 20 & 58 & 2 & 11 \\
\hline 12 & $\mathrm{~A}_{3}$ & $\mathrm{~B}_{4}$ & $\mathrm{C}_{2}$ & $\mathrm{D}_{1}$ & $E_{3}$ & 5 & 21.5 & 60 & 0 & 10 \\
\hline 13 & $\mathrm{~A}_{4}$ & $\mathrm{~B}_{1}$ & $\mathrm{C}_{4}$ & $D_{2}$ & $E_{3}$ & 6 & 17 & 64 & 2 & 10 \\
\hline 14 & $\mathrm{~A}_{4}$ & $\mathrm{~B}_{2}$ & $\mathrm{C}_{3}$ & $\mathrm{D}_{1}$ & $E_{4}$ & 6 & 18.5 & 62 & 0 & 11 \\
\hline 15 & $\mathrm{~A}_{4}$ & $\mathrm{~B}_{3}$ & $\mathrm{C}_{2}$ & $\mathrm{D}_{4}$ & $\mathrm{E}_{1}$ & 6 & 20 & 60 & 6 & 7 \\
\hline 16 & $\mathrm{~A}_{4}$ & $\mathrm{~B}_{4}$ & $\mathrm{C}_{1}$ & $D_{3}$ & $E_{2}$ & 6 & 21.5 & 58 & 4 & 8 \\
\hline
\end{tabular}

\section{Orthogonal Test Analysis and Determination of the Optimal Trial Protocol}

According to the orthogonal test scheme, we carried out numerical simulations for pumps in 16 experimental trials (Table 8). Firstly, we analyzed the test results directly. Then, we performed a range analysis for the selected levels of the factors in the orthogonal test. Finally, the optimal trial protocol was determined based on the weight function.

Table 8. Performance of the numerical simulation.

\begin{tabular}{ccc}
\hline Trial No. & Head $(\mathbf{m})$ & Efficiency $(\%)$ \\
\hline 1 & 10.12 & 46.44 \\
2 & 13.04 & 56.69 \\
3 & 7.62 & 34.00 \\
4 & 10.06 & 42.72 \\
5 & 8.26 & 46.92 \\
6 & 9.16 & 48.20 \\
7 & 7.42 & 35.51 \\
8 & 8.76 & 42.63 \\
9 & 15.16 & 68.64 \\
10 & 15.43 & 66.67 \\
11 & 6.42 & 33.65 \\
12 & 6.58 & 32.01 \\
13 & 16.16 & 68.47 \\
14 & 12.71 & 57.12 \\
15 & 6.79 & 41.45 \\
16 & 8.09 & 46.68 \\
\hline
\end{tabular}

\subsection{Analysis of the Orthogonal Test Results}

Table 8 shows the numerical simulation results for the 16 test pumps at the rated flow rate $\left(\mathrm{Q}=100 \mathrm{~m}^{3} / \mathrm{h}\right)$ with $\mathrm{IGVF}=15 \%$. The results of the 16 trials were analyzed directly with a single index. In this study, the optimized indices were the head and efficiency of the multiphase pump. The trial with the optimal head was No. 13, and the trial protocol 
was $\mathrm{A}_{4} \mathrm{~B}_{1} \mathrm{C}_{4} \mathrm{D}_{2} \mathrm{E}_{3}$, in which $\beta_{\mathrm{I}, \mathrm{s} 1}=6^{\circ} ; \beta_{\mathrm{I}, \mathrm{s} 2}=17^{\circ} ; \mathrm{L}=64 \mathrm{~mm} ; \Delta \beta_{\mathrm{D}}=2^{\circ} ;$ and $\mathrm{Z}_{\mathrm{D}}=10$. The trial with optimal efficiency was No. 9 , and the trial protocol was $\mathrm{A}_{3} \mathrm{~B}_{1} \mathrm{C}_{3} \mathrm{D}_{4} \mathrm{E}_{2}$, in which $\beta_{\mathrm{I}, \mathrm{s} 1}=5^{\circ} ; \beta_{\mathrm{I}, \mathrm{s} 2}=17^{\circ} ; \mathrm{L}=62 \mathrm{~mm} ; \Delta \beta_{\mathrm{D}}=6^{\circ} ;$ and $\mathrm{Z}_{\mathrm{D}}=8$.

The range analysis was carried out to analyze the influence of each factor on the optimized indices. The greater the range, the greater the influence of the selected level of the factor on the indices. Range analysis was carried out on the numerical results of the orthogonal test in Table $8 ; k_{i}$ was the average value of a single index at a certain level of different factors, and was calculated using Equation (11). $\mathrm{R}$ is the range of the factor, which is the difference between the maximum value and minimum value of $k_{i}$, and was calculated using Equation (12). The results are shown in Table 8.

$$
\begin{gathered}
k_{i}=\frac{1}{4} \sum_{i=1}^{4} y_{i j} \\
\mathrm{R}=\max \left\{k_{i}\right\}-\min \left\{k_{i}\right\}, i=1,2,3,4
\end{gathered}
$$

where $i$ denotes different levels; $j$ denotes different factors; and $y_{i j}$ denotes the index value of factor $j$ at level $i$.

Table 9 shows the influence law of various factors on the head and efficiency indices. Among the factors, the sequence of each factor that affected the head index was $\beta_{\mathrm{I}, \mathrm{s} 2}>\mathrm{L}>\beta_{\mathrm{I}, \mathrm{s} 1}>\Delta \beta_{\mathrm{D}}>\mathrm{Z}_{\mathrm{D}}$, and the sequence of each factor that affected the efficiency index was $\beta_{\mathrm{I}, \mathrm{s} 2}>\beta_{\mathrm{I}, \mathrm{s} 1}>\mathrm{L}>\Delta \beta_{\mathrm{D}}>\mathrm{Z}_{\mathrm{D}}$. The first three factors that had a great influence on the head and efficiency indices were the blade shroud angle at the trailing edge $\left(\beta_{\mathrm{I}, \mathrm{s} 2}\right)$, axial length $(\mathrm{L})$, and blade angle at the leading edge $\left(\beta_{\mathrm{I}, \mathrm{s} 1}\right)$, all of which were parameters within the impeller. Among these three factors, the blade shroud angle at the trailing edge $\left(\beta_{\mathrm{I}, \mathrm{s} 2}\right)$ had the greatest influence on the head and efficiency indices. The inlet incidence angle and the number of blades of the diffuser had less influence on the head and efficiency indices, which demonstrated that the design and optimization of the impeller in the pressurization unit of the multiphase pump were more important than the diffuser.

Table 9. Range analysis.

\begin{tabular}{ccccccccccc}
\hline & \multicolumn{3}{c}{$\mathbf{H} / \mathbf{m}$} & \multicolumn{7}{c}{$\eta / \%$} \\
\hline & $\beta_{\mathbf{I}, \mathbf{s} \mathbf{}}$ & $\beta_{\mathbf{I}, \mathbf{s} \mathbf{2}}$ & $\mathbf{L}$ & $\boldsymbol{\Delta} \boldsymbol{\beta}_{\mathbf{D}}$ & $\mathbf{Z}_{\mathbf{D}}$ & $\beta_{\mathbf{I}, \mathbf{s} \mathbf{1}}$ & $\boldsymbol{\beta}_{\mathbf{I}, \mathbf{s} \mathbf{2}}$ & $\mathbf{L}$ & $\boldsymbol{\Delta} \boldsymbol{\beta}_{\mathbf{D}}$ & $\mathbf{Z}_{\mathbf{D}}$ \\
\hline$k_{1}$ & 10.21 & 12.42 & 8.50 & 9.21 & 10.27 & 44.96 & 57.62 & 43.74 & 42.77 & 49.36 \\
$k_{2}$ & 8.40 & 12.51 & 8.67 & 11.10 & 10.92 & 43.32 & 57.17 & 44.26 & 50.36 & 51.88 \\
$k_{3}$ & 10.90 & 7.06 & 11.06 & 9.85 & 9.88 & 50.24 & 36.15 & 50.60 & 48.57 & 45.68 \\
$k_{4}$ & 10.94 & 8.37 & 12.26 & 10.34 & 9.36 & 53.43 & 41.00 & 53.34 & 48.91 & 45.10 \\
$\mathrm{R}$ & 2.50 & 5.45 & 3.76 & 1.89 & 1.56 & 10.11 & 21.47 & 9.60 & 7.59 & 6.78 \\
Rank & 3 & 1 & 2 & 4 & 5 & 2 & 1 & 3 & 4 & 5 \\
\hline
\end{tabular}

To more intuitively observe the impact of various factors on the efficiency and head indices of the multiphase pump, index response curves were drawn with the level of factor as the $\mathrm{x}$-coordinate, and the head and efficiency indices as the $\mathrm{y}$-coordinate, as shown in Figure 5 . It can be seen in Figure 5 that the factor $\beta_{\mathrm{I}, \mathrm{s} 2}$ (blade shroud angle at the trailing edge of the impeller) and factor $L$ (axial length of the impeller) had particularly obvious influences on the head and efficiency indices. When the level of factor $\left(\beta_{\mathrm{I}, \mathrm{s} 2}\right)$ was small, the head and efficiency indices were in a good condition. When the level of factor $\left(\beta_{\mathrm{I}, \mathrm{s} 2}\right)$ was large, both the head and efficiency indices dropped significantly. In theory, the greater the blade angle at the trailing edge of the impeller, the higher the head of the pump. However, the absolute velocity increases with the increment of the blade angle at the impeller outlet, resulting in an increase in the hydraulic loss of fluid in the pump. In addition, during the transportation of the gas-liquid mixture, the separation of the gas and liquid phases in the impeller was intensified in the direction perpendicular to the flow, with an increase in the blade angle at the impeller outlet. More gas gathered on the blade suction side of 
the impeller, resulting in a further increase in turbulence loss in the impeller. Therefore, with the increase of $\beta_{\mathrm{I}, \mathrm{s} 2}$, the head and efficiency indices tended to increase first, and then decrease rapidly. As the level of factor $L$ rose, both the head and efficiency indices improved. The reasons were as follows: within a certain range of the impeller axial length, the longer the axial length, the larger the blade area, and the greater the pressurization ability. Meanwhile, the decrease in the impeller blade distortion degree led to a weakened separation of the gas and liquid phases in the direction perpendicular to the flow, thus contributing to better indices for the head and efficiency.

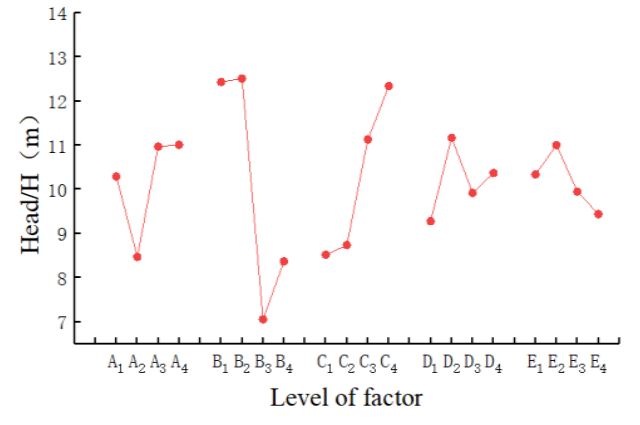

(a)

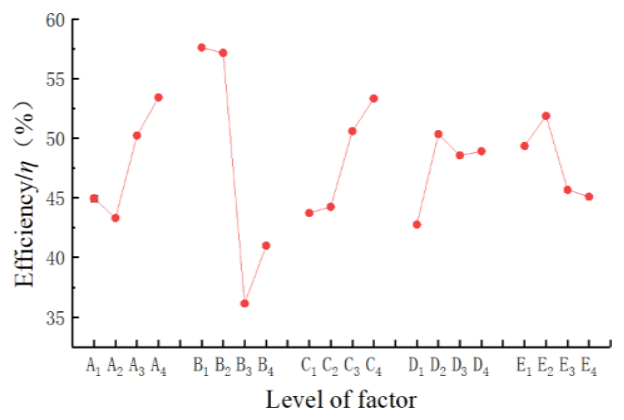

(b)

Figure 5. Response curves of each factor with indices. (a) Relationships between each factor and head index; (b) relationships between each factor and efficiency index.

\subsection{Best Trial Protocol Is Determined According to the Weight Function}

In general, regardless of the interaction between factors, if there was only one index when we analyzed the influence of factors on the index, the combination of each factor at the best level would be the best trial protocol. As can be seen in Figure 5, the best trial protocol was $\mathrm{A}_{4} \mathrm{~B}_{2} \mathrm{C}_{4} \mathrm{D}_{2} \mathrm{E}_{2}$ when the head was taken as the only optimized index, while the best trial protocol was $\mathrm{A}_{4} \mathrm{~B}_{1} \mathrm{C}_{4} \mathrm{D}_{2} \mathrm{E}_{2}$ when the efficiency was taken as the only optimized index. When the head and efficiency were taken as the optimized indices, the best trial protocol of factors $\beta_{\mathrm{I}, \mathrm{s} 1}, \mathrm{~L}, \Delta \beta_{\mathrm{D}}, \mathrm{Z}_{\mathrm{D}}$ was $\mathrm{A}_{4} \mathrm{C}_{4} \mathrm{D}_{2} \mathrm{E}_{2}$, but the level of factor $\beta_{\mathrm{I}, \mathrm{s} 2}$ could not be determined.

Therefore, the weight function $F_{i}$ was introduced to convert the two indices into a single one. The head and efficiency were given different weights of $a$ and $b$, respectively. The optimized indices of this test were the efficiency and head of the multiphase pump, and since both these indices were of great importance to the multiphase pump, $a$ and $b$ were given as 0.5 and 0.5 , respectively.

$$
\begin{aligned}
& F_{i}=a H_{i}^{\prime}+b \eta_{i}^{\prime} \\
& H_{i}^{\prime}=\frac{k_{i}}{H} \eta_{i}^{\prime}=\frac{k_{i}}{\eta}
\end{aligned}
$$

where $H$ is the head $(H=13.36 \mathrm{~m})$ of the base pump under the rated flow rate with IGVF $=15 \% ; \eta$ is the efficiency $(\eta=63 \%)$ of the base pump under the rated flow rate with IGVF $=15 \%$; and $k_{i}$ is the mean value of the head/efficiency in different factors at a certain level.

According to the weight function, the best trial protocol was determined as $\mathrm{A}_{4} \mathrm{~B}_{1} \mathrm{C}_{4} \mathrm{D}_{2} \mathrm{E}_{2}$; that is, blade shroud angle at the leading edge $\beta_{\mathrm{I}, \mathrm{s} 1}=6^{\circ}$; blade shroud angle at the trailing edge $\beta_{\mathrm{I}, \mathrm{s} 2}=17^{\circ}$; axial length of the impeller $\mathrm{L}=64 \mathrm{~mm}$; inlet incidence angle at the inlet of the diffuser $\Delta \beta_{D}=2^{\circ}$; and blade number of the diffuser $Z_{D}=8$. The model was generated with the above geometric parameters and numerically simulated under the rated flow rate with IGVF $=15 \%$. The simulation results showed an efficiency of $68.6 \%$ and a head of $16.17 \mathrm{~m}$. Compared with the base model, the efficiency and head increased by $5.6 \%$ and $2.81 \mathrm{~m}$, respectively, which proved that the optimization of the orthogonal test method 
combined with the weight function was feasible. Figure 6 shows the comparison of the impeller and diffuser before and after the optimization. The black color represents the optimized pump, while the red color represents the base pump. In order to obtain a better understanding of the geometric differences between the two models before and after the optimization, only one blade is shown for the impeller and diffuser of the base pump.

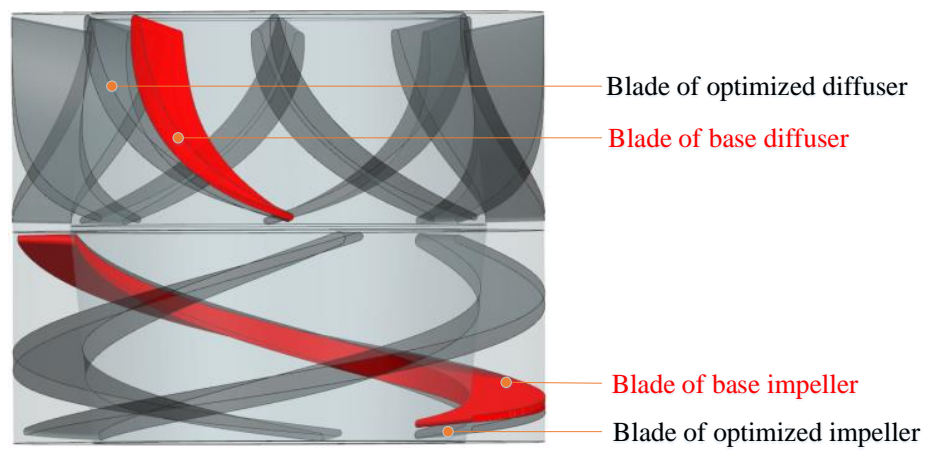

Figure 6. Model shape comparison of the base and optimized pumps.

\section{Comparison of the Two Models}

For the purpose of comparing the optimized results with the original ones, in this study, the differences between the base pump and optimized pump were compared and analyzed using aspects such as hydraulic performance, energy conversion characteristics, and internal flow field. The conditions under the rated flow rate with IGVF $=15 \%$ were taken as an example of the energy conversion characteristics and internal flow field.

Figure 7 shows the comparison of the hydraulic performance curves between the base pump and optimized pump. As can be seen when comparing Figure $7 \mathrm{a}, \mathrm{b}$, the efficiency and head of the optimized pump greatly improved compared with the base pump under the gas-liquid two-phase conditions, but the improvement of the performance under pure water conditions was not significant. This was because the purpose of this study was to optimize the transport performance under gas-liquid two-phase conditions, so the improvement of efficiency and head under pure water conditions was of less importance. As can be seen in Figure 7a, in the gas-liquid two-phase conditions, the head and efficiency of the base pump declined rapidly with the increase of the inlet gas volume fraction. When the inlet gas volume fraction increased from $10 \%$ to $20 \%$, the efficiency of the base pump decreased by $7.66 \%$. However, with the increase of the inlet gas volume fraction, the efficiency of the optimized pump changed slightly, and the decrease for the head was not as obvious as the previous one. As the inlet gas volume fraction reached $20 \%$, compared with the base pump, the efficiency and head of the optimized pump increased by $9.64 \%$ and $3.5 \mathrm{~m}$, respectively. This indicated that the optimization results were very successful for the purpose of gas-liquid transport performance. It can be seen in Figure $7 \mathrm{~b}$ that in the pure water conditions, the efficiency of the optimized pump increased at all points, especially at the points for conditions of a low flow rate. The head was increased at the points of $0.9 \mathrm{Q}_{\mathrm{d}}, 1.0 \mathrm{Q}_{\mathrm{d}}$, and $1.1 \mathrm{Q}_{\mathrm{d}}$, while it changed slightly at the points of $0.8 \mathrm{Q}_{\mathrm{d}}$ and $1.2 \mathrm{Q}_{\mathrm{d}}$. Compared with the base pump, the efficiency and head of the optimized pump increased by $1.47 \%$ and $1 \mathrm{~m}$, respectively, at the point of $1.0 \mathrm{Q}_{\mathrm{d}}$. 


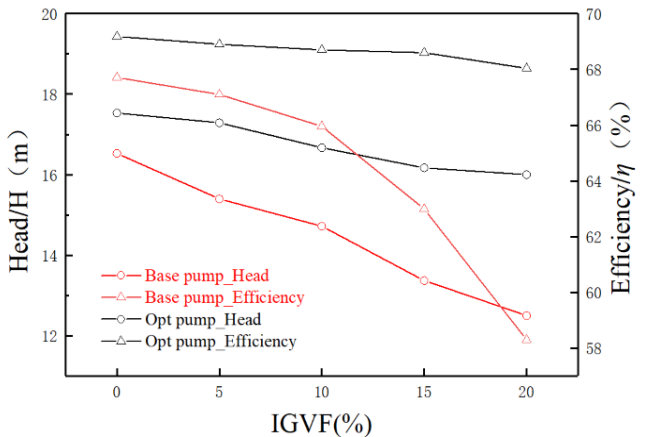

(a)

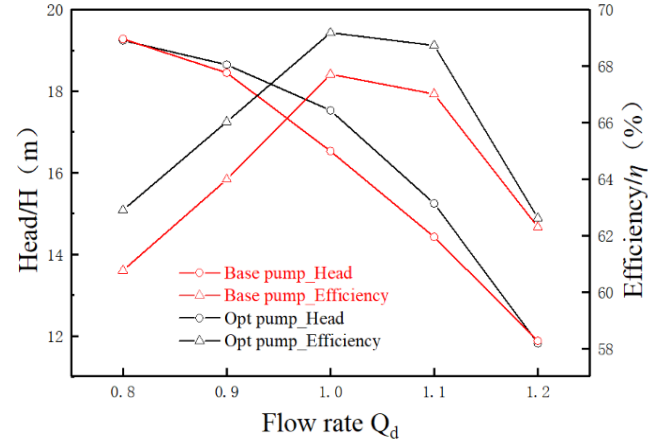

(b)

Figure 7. Performance curve comparison for the base and optimized pumps: (a) under the designed flow rate with different IGVFs, and (b) under different flow rate conditions.

For the purpose of facilitating the analysis of the internal energy conversion in the impellers and diffusers, the impellers and diffusers were respectively and evenly divided into 10 areas along the flow direction. From the inlet to the outlet of the impeller and diffuser, the 10 areas were named as $1,2, \ldots$ and 10 in turn. Figure 8 shows the variation of the head in each area of the impeller and diffuser. A major increase occurred for the head in the base impeller in the middle, while a major increment occurred for the head in the optimized impeller in the first half. Moreover, the increment of the head in each area of the base impeller changed greatly. Region 4 had the maximum head increment, while region 1 had the minimum head increment; the range of head increment in each area was $2.21 \mathrm{~m}$. After the optimization, the head increment in each area of the impeller changed little. The area with the maximum head increment was region 4 , while the area with the minimum head increment was region 10; the range of head increment in each area was $0.89 \mathrm{~m}$, which indicated that the work capacity of various areas in the optimized impeller was more uniform. The total increment of the head in each area of the base impeller was $21.25 \mathrm{~m}$, and the total increment of the head in each area of the optimization impeller was $23.7 \mathrm{~m}$, which was improved by $2.45 \mathrm{~m}$ compared with the base impeller.

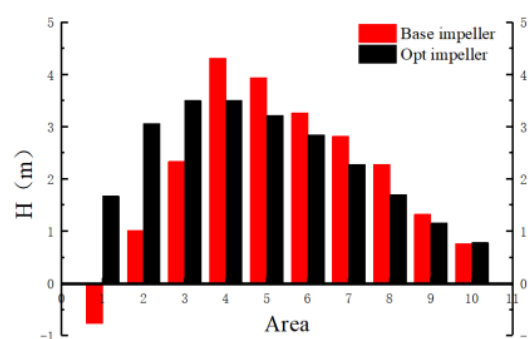

(a)

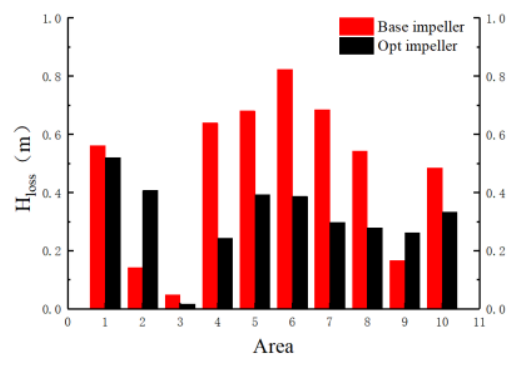

(b)

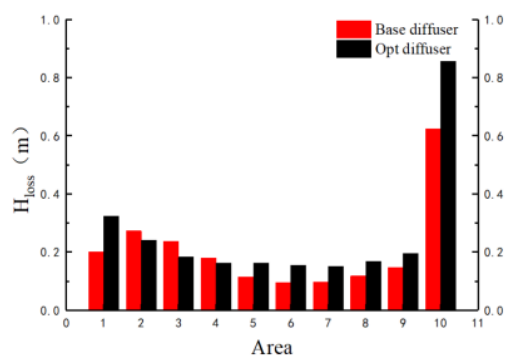

(c)

Figure 8. Variation of the head in each area of the impellers and diffusers before and after the optimization. (a) Head increment; (b) head loss of the impellers; (c) head loss of the diffusers.

It can be seen in Figure 8b,c that the total head loss in each area of the impellers was greater than that of the diffusers, which also indicated that the optimization and design of the impeller were more important than the diffuser. Meanwhile, in comparison with the head loss in each area of the base and optimized impellers, it was found that the areas with large head loss were the middle areas of the base impeller, referring to regions 4, 5, 6, 7, and 8 . After the optimization, the head loss in these regions was reduced greatly. The sum of the head loss in each area of the base impeller was $4.78 \mathrm{~m}$, while the sum of head loss in each area of the optimized impeller was $3.14 \mathrm{~m}$. After the optimization, the head loss in the impeller was reduced by $1.64 \mathrm{~m}$. 
It can be seen in Figure $8 c$ that the head losses of the base diffuser and optimized diffuser were mainly in the inlet and outlet areas. Meanwhile, the head loss in region 10 was much larger than that of other areas. The large head loss at the inlet areas of the diffuser was caused by the rotation of the impeller. The reasons for the large head loss at the outlet of the diffuser were as follows: on the one hand, the diffusible structure of the diffuser caused the formation of the vortex at the exit of the diffuser, which resulted in a large turbulence loss; on the other hand, the backflow from the outlet pipe section caused a secondary impact on the blade trailing edge of the diffuser, leading to a partial impact loss.

The generation of a vortex seriously affected the internal flow field and hydraulic performance of the pump. To a certain extent, the inner flow in the pump could be judged from the structure and size of the vortex. The $Q$ criterion can effectively eliminate the interference of the shear layer to the vortex structure, and identify the vortex structure in the pump accurately and clearly. In this study, the vortex structure in the flow passage of the multiphase pump before and after the optimization was extracted by the recognition of the $\mathrm{Q}$ criterion and the selection of the threshold value of 0.015 , as shown in Figure 9. It can be seen in Figure 9 that the major vortex structures in the base impeller consisted of the attached vortex on the hub, the mass vortex on the blade suction side, and the trailing edge vortex at the impeller outlet. After the optimization, the mass vortex on the blade suction side disappeared, and the size of the attached vortex at the hub and trailing edge vortex at the impeller outlet became smaller, which indicated that the overall inner flow in the impeller improved after the optimization. In particular, the vortices at the blade suction surface and the outlet of the impeller were obviously weakened. Compared with the impellers, the size of the vortex structure in the diffusers was smaller and less variable.

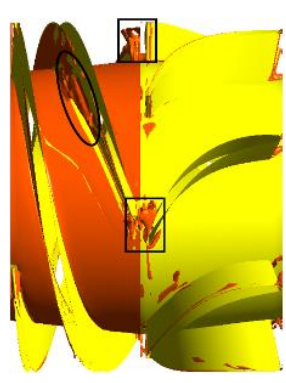

(a)

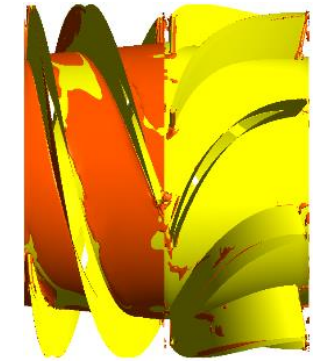

(b)

Figure 9. Identification of the internal vortex structure in the base and optimized pumps based on the $\mathrm{Q}$ criterion. (a) The base pump; (b) the optimized pump.

Figure 10 shows the distributions of the static pressure curves at different blade heights $(20 \%, 50 \%, 80 \%)$ of the impeller blade before and after the optimization. As can be seen in Figure 10, the static pressure on the blade suction surface at the impeller inlet of the base pump was greater than that on the blade pressure surface. The static pressure curves of the blade pressure surface and suction surface intersected at the 0.1 blade relative location. This was because the blade angle at the impeller inlet was smaller than the flow angle, and the difference between the blade angle and flow angle was the negative incidence angle, which can easily cause the formation of a vortex and the accumulation of gas phase at the leading edge of the blade. Meanwhile, it also can be used to explain the negative increment of the head in region 1 of Figure 8a. At the inlet of the optimization impeller, the static pressure on the blade pressure surface was slightly higher than that on the suction surface at each blade height, which indicated that the blade angle at the leading edge was reasonable after the optimization. At the blade relative location of approximately 0.4 times, the areas with partially low pressure appeared at the blade suction surface at each blade height of the base impeller, and cavitation was likely to occur in the partially low-pressure areas, usually leading to energy loss in the impeller. After the optimization, the static pressure value for the blade suction surface gradually increased from the blade 
relative location by approximately 0.2 times, and the partially low-pressure areas vanished. When comparing the static pressure values for the blade pressure surface and the suction surface of the impellers before and after the optimization, respectively, it can be seen that the static pressure values of the blade pressure and suction side of the optimized impeller were much larger than those of the base impeller from the inlet to the outlet, which was conducive to the suppression of cavitation, indicating a better cavitation performance of the optimized impeller.

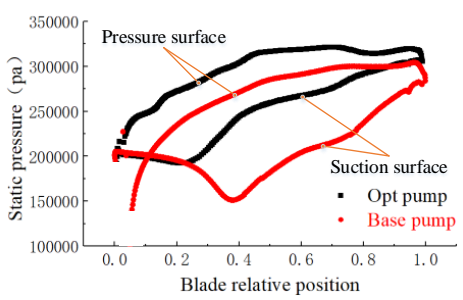

$20 \%$

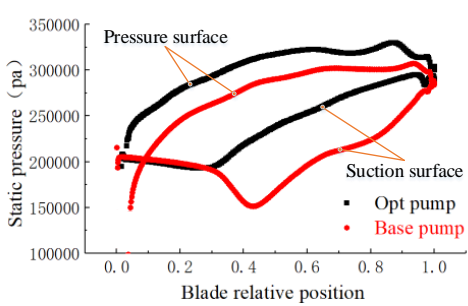

$50 \%$

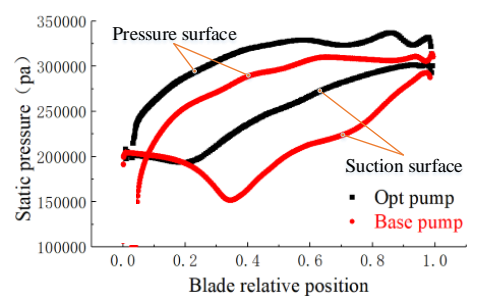

$80 \%$

Figure 10. Distributions of the static pressure curves with different blade heights.

Figure 11 shows the velocity distribution of the liquid phase at different sections (20\%, $50 \%, 80 \%$ ) of blade heights for the base and optimized pumps. As shown in Figure 11a, firstly, there were partial fast-speed areas at the inlet of the base impeller passages (as shown in the black rectangular box). On the one hand, the formation of the partial fastspeed areas was due to the small blade angle at the impeller inlet, resulting in a small excretion coefficient at the inlet. On the other hand, the location where the maximum blade thickness was just at the inlet of adjacent blade led to a narrow flow channel and fluid acceleration, thus the appearance of the partial fast-speed and partial low-pressure areas on the blade suction side corresponding to Figure 10. After the optimization of the blade angle at the leading edge of the impeller, the partial speed areas at the inlet of the passage disappeared. Secondly, in the base pump, there were partial low-speed areas on the blade suction surface at the impeller outlet. The most obvious low-speed area appeared at the section of $80 \%$ blade height. From the section of $20 \%$ to $80 \%$ blade height, the low-speed area moved toward the impeller outlet. After the optimization, the low-speed areas on the blade suction surface at different sections of blade height disappeared, and velocity increased uniformly from the inlet to the outlet of the impeller channels, forming a better flow status in the impeller channels. By comparing the liquid-phase velocity distribution in the diffusers before and after the optimization, it was found that the scale of the low-speed areas in the diffuser was reduced, especially at the sections of $20 \%$ and $50 \%$ blade height, which also indicated a better flow status in the diffuser. 


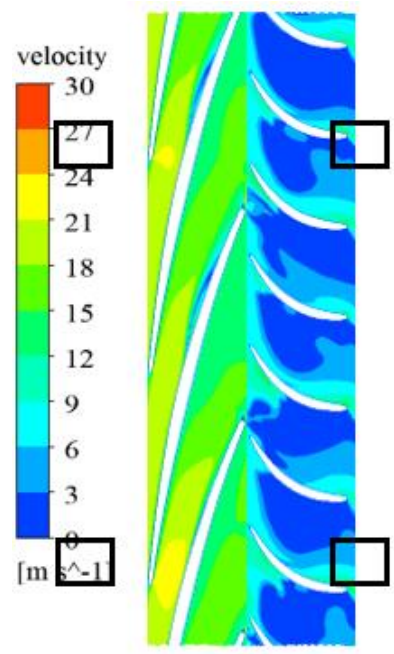

$20 \%$

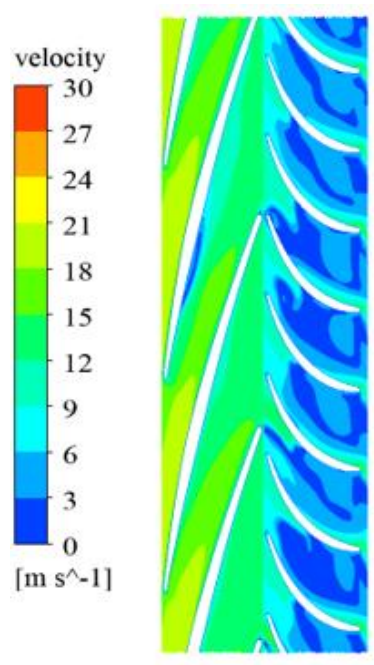

$20 \%$

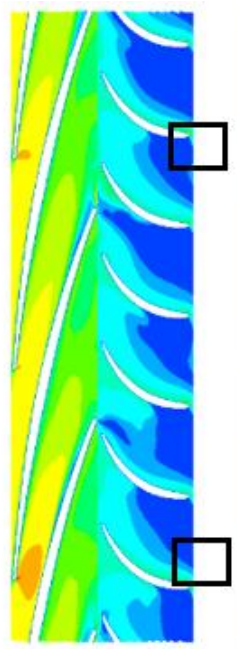

$50 \%$

(a)

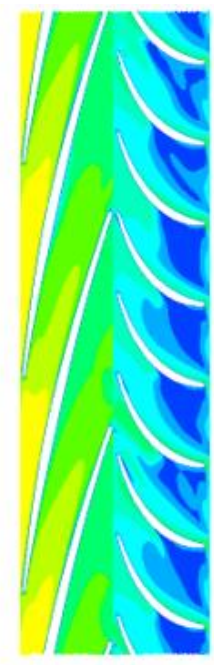

$50 \%$

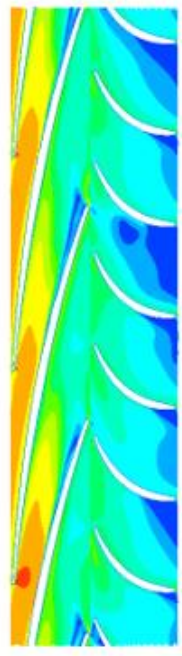

$80 \%$

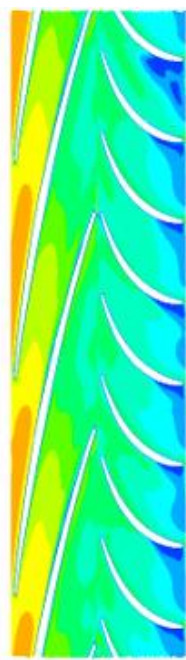

$80 \%$

(b)

Figure 11. Velocity distribution of liquid phase at different sections of blade height for the base and optimized pump. (a) The base pump, (b) The optimization pump.

Figure 12 shows the distribution of the gas phase at sections $(20 \%, 50 \%, 80 \%)$ of the blade height in the base pump and optimized pump. In the base pump, it can be seen in Figure 12a that gas accumulated at the blade suction side of the impeller outlet. The most obvious accumulation of the gas phase occurred at the section of $80 \%$ blade height, which refers to the low-speed areas on the blade suction side of the impeller shown in Figure 11a. This indicated that the accumulation of the gas phase could slow the velocity of the liquid phase. After the optimization, the accumulation degree of the gas phase on the blade suction side of the impeller was weakened, and the accumulation of the gas phase was apparent only at the section of $80 \%$ blade height of the impeller. This proved that the separation of the gas and liquid phases in the impeller was weakened after the optimization. 


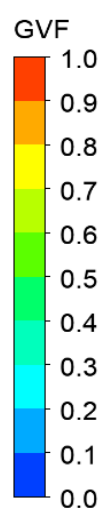

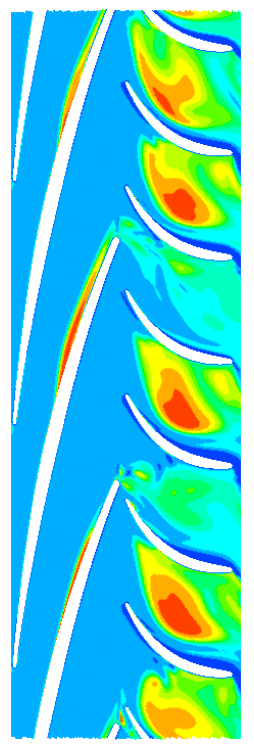

$20 \%$

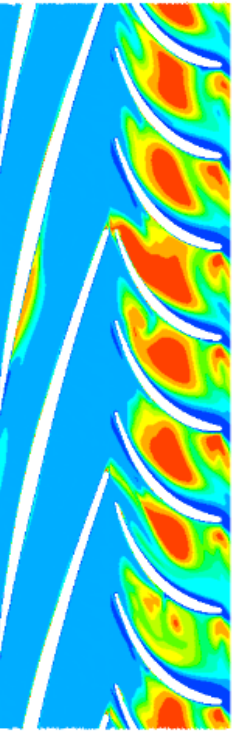

$20 \%$

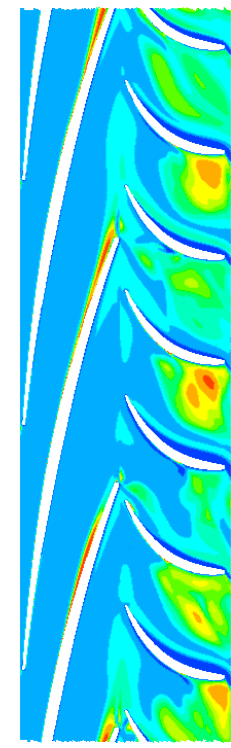

$50 \%$

(a)

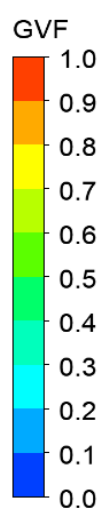

GVF
\begin{tabular}{|l}
1.0 \\
0.9 \\
0.8 \\
0.7 \\
0.6 \\
0.5 \\
0.4 \\
0.3 \\
0.2 \\
0.1 \\
0.0
\end{tabular}

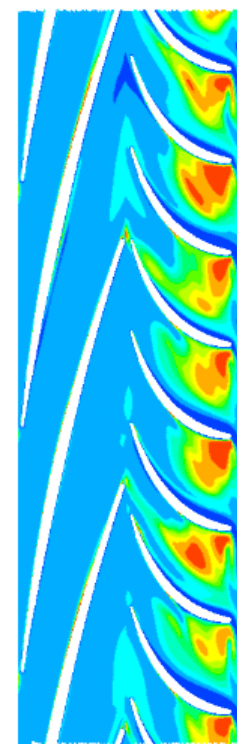

$50 \%$

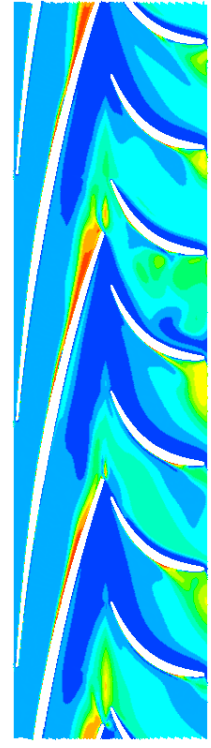

$80 \%$

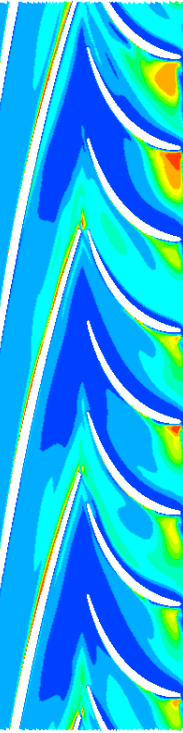

$80 \%$

(b)

Figure 12. Distribution of gas phase at different sections of blade height in the base and optimized pumps. (a) The base pump; (b) the optimized pump.

\section{Conclusions}

To improve the transport performance of the rotodynamic multiphase pump for a gas-liquid mixture, the orthogonal test design method and CFD technology were used, using the head and efficiency as the optimization indices. The blade shroud angles at the leading edge and trailing edge, the axial length of the impeller, the inlet incidence angle, and the blade number of the diffuser were selected as the test factors, with four levels for each. In order to obtain a similar head of fluid at different blade heights in the impeller, the corresponding blade hub angles at the leading edge and trailing edge of the impeller were calculated according to the principle of radial lead equality. The flow angles at the inlet of the diffuser were calculated according to the blade angles at the outlet of the impeller 
and the velocity moment theorem. Finally, under the rated flow rate with a $15 \%$ inlet gas volume fraction, we carried out the orthogonal test according to the orthogonal test scheme $\mathrm{L}_{16}\left(4^{5}\right)$. The following conclusions were drawn:

(1) The first three factors that influenced the head and efficiency indices were the blade shroud angles at the trailing and leading edges of the impeller, and the axial length of the impeller. Among those factors, the blade shroud angle at the trailing edge had the greatest influence on the efficiency and head indices, indicating that the blade shroud angle at the trailing edge is a very important parameter in a multiphase pump.

(2) Under the rated flow rate with $15 \%$ inlet gas volume fraction, the efficiency and head of the optimized pump increased by $5.6 \%$ and $2.81 \mathrm{~m}$, respectively, compared with the base pump.

(3) The optimization of the blade angle at the leading edge of the impeller resulted in the disappearance of both the partial high-speed areas at the inlet of the impeller passages and the partial low-pressure areas on the blade suction side of the impeller, while the optimization of the blade angle at the trailing edge and axial length of the impeller resulted in a reduction of the gas accumulation on the blade suction side at the impeller outlet. The optimized pump achieved a better flow state in the impeller, and the pressurizing and conveying capacity for the gas-liquid mixture was greatly improved after the optimization.

Author Contributions: Conceptualization, G.S.; methodology, H.L.; software, H.L; validation, H.L., Z.L. and B.W.; formal analysis, G.S.; investigation, X.L.; resources, X.L.; data curation, G.S.; writingoriginal draft preparation, H.L.; writing—review and editing, G.S.; visualization, Z.L.; supervision, B.W.; project administration, B.W.; funding acquisition, B.W. All authors have read and agreed to the published version of the manuscript.

Funding: This work was supported by the National Key Research and Development Program (2018YFB0905200), Open Research Fund Program of State Key Laboratory of Hydroscience and Engineering (sklhse-2021-E-03), and the Key scientific research fund of Xihua University of China (Grant No. Z1510417).

Institutional Review Board Statement: Not applicable.

Informed Consent Statement: Not applicable.

Data Availability Statement: All the data is already in the article.

Conflicts of Interest: The authors declare no conflict of interest.

\section{References}

1. Liu, Y.B.; Tan, L. Method of C groove on vortex suppression and energy performance improvement for a NACA0009 hydrofoil with tip clearance in tidal energy. Energy 2018, 155, 448-461. [CrossRef]

2. Bauer, N.; Hilaire, J.; Brecha, R.J.; Edmonds, J.; Jiang, K.J.; Kriegler, E.; Rogner, H.H.; Sferra, F. Assessing global fossil fuel availability in a scenario framework. Energy 2016, 111, 580-592. [CrossRef]

3. Shi, Y.; Zhu, H.; Zhang, J.; Zhang, J.; Zhao, J. Experiment and numerical study of a new generation three-stage multi-phase pump. J. Pet. Sci. Eng. 2018, 169, 471-484. [CrossRef]

4. Zhang, J.; Cai, S.; Li, Y.; Zhu, H.; Zhang, Y. Visualization study of gas-liquid two-phase flow patterns inside a three-stage rotodynamic multiphase pump. Exp. Therm. Fluid Sci. 2016, 70, 125-138. [CrossRef]

5. Zhang, W.; Yu, Z.; Zahid, M.; Li, Y. Study of the Gas Distribution in a Multiphase Rotodynamic Pump Based on Interphase Force Analysis. Energies 2018, 11, 1069. [CrossRef]

6. Shi, G.T.; Wang, Z.W.; Wang, Z.W.; Li, Z.G.; Liu, X.B. Research on the pressurization performance of an impeller in a multi-phase pump under different working conditions. Adv. Mech. Eng. 2019, 11, 1687814019827144. [CrossRef]

7. Shi, G.; Liu, Z.; Xiao, Y.; Wang, Z.; Luo, Y.; Luo, K. Energy conversion characteristics of multiphase pump impeller analyzed based on blade load spectra. Renew. Energy 2020, 157, 9-23. [CrossRef]

8. Zhang, W.; Yu, Z.; Zhu, B. Numerical Study of Pressure Fluctuation in a Gas- Liquid Two-Phase Mixed-Flow Pump. Energies 2017, 10, 634. [CrossRef]

9. Cao, S.L.; Peng, G.Y.; Yu, Z.Y. Hydrodynamic design of rotodynamic pump impeller for multiphase pumping by combined approach of inverse design and CFD analysis. J. Fluids Eng. Trans. Asme 2005, 127, 330-338. [CrossRef]

10. Li, Y.J. Stage by Stage Design of Impellers in a Multi-Stage Gas-Liquid Multiphase Pump Considering the Compressibility of Gas; China University of Petroleu (Beijing): Beijing, China, 2017. 
11. Shi, Y.; Zhu, H.; Yin, B.; Xu, R.; Zhang, J. Numerical investigation of two-phase ow characteristics in multiphase pump with split vane impellers. J. Mech. Sci. Technol. 2019, 33, 1651-1661. [CrossRef]

12. Xu, Y.; Cao, S.; Reclari, M.; Wakai, T.; Sano, T. Multiphase performance and internal flow pattern of rotodynamic pumps. IOP Conf. Ser. Earth Environ. Sci. 2019, 240, 032029. [CrossRef]

13. Liu, M.; Tan, L.; Cao, S. Design Method of Controllable Blade Angle and Orthogonal Optimization of Pressure Rise for a Multiphase Pump. Energies 2018, 11, 1048. [CrossRef]

14. Kim, J. Multi objective optimization of a multiphase pump for offshore plants. In Proceedings of the ASME 20144 th Joint US-European Fluids Engineering Division Summer Meeting 2014, Chicago, IL, USA, 3-7 August 2014.

15. Kim, J.H.; Lee, H.C.; Kim, J.H.; Choi, Y.S.; Yoon, J.Y.; Yoo, I.S.; Choi, W.C. Improvement of Hydrodynamic Performance of a Multiphase Pump Using Design of Experiment Techniques. J. Fluids Eng. Trans. Asme 2015, 137, 081301. [CrossRef]

16. Suh, J.W.; Kim, J.H.; Choi, Y.S.; Joo, W.G.; Lee, K.Y. A study on numerical optimization and performance verification of multiphase pump for offshore plant. Proc. Inst. Mech. Eng. Part A J. Power Energy 2017, 231, 382-397. [CrossRef]

17. Zhang, J.; Zhu, H.; Yang, C.; Li, Y.; Wei, H. Multi-objective shape optimization of rotodynamic multiphase pump impeller based on NSGA-II and ANN. Energy Convers. Manag. 2011, 52, 538-546. [CrossRef]

18. Hu, H.; Li, X.; Gu, B. Hydraulic Optimization of Multiphase Pump Based on CFD and Genetic Algorithm. Int. J. Grid Distrib. Comput. 2015, 8, 161-169.

19. Suh, J.W.; Kim, J.W.; Choi, Y.S.; Kim, J.H.; Joo, W.G.; Lee, K.Y. Multi-Objective Optimization of the Hydrodynamic Performance of the Second Stage of a Multi-Phase Pump. Energies 2017, 10, 1334. [CrossRef]

20. Li, Z.; Ding, H.; Shen, X.; Jiang, Y. Performance Optimization of High Specific Speed Centrifugal Pump Based on Orthogonal Experiment Design Method. Processes 2019, 7, 728. [CrossRef]

21. Xu, Y.; Tan, L.; Cao, S.L.; Qu, W.S. Multiparameter and multiobjective optimization design of centrifugal pump based on orthogonal method. Proc. Inst. Mech. Eng. Part C J. Mech. Eng. Sci. 2017, 231, 2569-2579. [CrossRef]

22. Quan, H.; Guo, Y.; Li, R.; Su, Q.; Chai, Y. Optimization design and experimental study of vortex pump based on orthogonal test. Sci. Prog. 2019, 103, 1-20. [CrossRef]

23. Perez, J.; Chiva, S.; Segala, W.; Morales, R.; Negrao, C.; Julia, E.; Hernandez, L. Performance Analysis of Flow in a Im-pellerDiffuser Centrifugal Pumps Using CFD: Simulation and Experimental Data Comparisons. Eur. Conf. Comput. Fluid Dyn. 2010, $6,14$.

24. Suh, J.W.; Kim, J.W.; Choi, Y.S.; Kim, J.H.; Joo, W.G.; Lee, K.Y. Development of numerical Eulerian-Eulerian models for simulating multiphase pumps. J. Pet. Sci. Eng. 2018, 162, 588-601. [CrossRef]

25. Zhang, J.Y.; Cai, S.J.; Li, Y.J.; Zhou, X.; Zhang, Y.X. Optimization design of multiphase pump impeller based on combined genetic algorithm and boundary vortex flux diagnosis. J. Hydrodyn. 2017, 29, 1023-1034. [CrossRef]

26. Zhang, Y.X.; Zhang, J.Y.; Zhu, H.W.; Cai, S.J. 3D Blade Hydraulic Design Method of the Rotodynamic Multiphase Pump Impeller and Performance Research. Adv. Mech. Eng. 2014, 6, 803972. [CrossRef]

27. Chris, R.; Michael, C.; Brad, H.; Robin, S. Impeller-diffsuer interaction in centrifugal compressors. In Proceedings of the ASME Turbo Expo 2012, Copenhagen, Denmark, 11-15 June 2012. 